\title{
Review
}

Pharmacology

\section{Darunavir: A Critical Review of Its Properties, Use and Drug Interactions}

\author{
Josilene Chaves Ruela Corrêa ${ }^{a}$ Deirdre M. D'Arcy ${ }^{c}$ \\ Cristina Helena dos Reis Serra ${ }^{b}$ Hérida Regina Nunes Salgado ${ }^{a}$ \\ aDrugs and Medicines Quality Control Laboratory, School of Pharmaceutical Sciences University Estadual \\ Paulista, Araraquara, and 'bSchool of Pharmaceutical Sciences University of São Paulo, São Paulo, Brazil; 'S School of \\ Pharmacy and Pharmaceutical Sciences, Trinity College Dublin, Dublin, Ireland
}

\section{Key Words \\ Darunavir · Human immunodeficiency virus · Acquired immune deficiency syndrome $\cdot$ Clinical pharmacokinetics • Drug interactions $\cdot$ Biopharmaceutics classification system}

\begin{abstract}
Darunavir is a synthetic nonpeptidic protease inhibitor which has been shown to be extremely potent against wildtype HIV as well as a large panel of PI-resistant clinical isolates and shows a high genetic barrier to the development of antiretroviral resistance. The treatment of HIV/AIDS requires combinations of multiple antiretroviral drugs. In addition, patients frequently need to coadminister other medications for reasons including the prevention or treatment of opportunistic infections, treatment of concomitant illnesses and management of antiretroviral side effects. Drug interactions have been observed between darunavir and other drugs. New and more comprehensive drug interaction studies will be required since the increase in life expectancy of patients often brings new comorbidities and the concomitant use of different drugs. This paper discusses the impact of the use of darunavir in the treatment of HIV-infected patients, its pharmacological and physical-chemical properties, its drug interactions, and challenges that remain in order to ensure safety and compliance of treatment.
\end{abstract}

Copyright $\odot 2012$ S. Karger AG, Basel
(C) 2012 S. Karger AG, Basel

0031-7012/12/0902-0102\$38.00/0

Fax +41613061234

E-Mail karger@karger.ch

www.karger.com
Accessible online at: www.karger.com/pha

\section{Introduction}

Human immunodeficiency virus (HIV) and the related acquired immune deficiency syndrome (AIDS), has claimed over 34 million lives since its discovery in $1981[1,2]$. According to the World Health Organization (WHO) AIDS epidemic updates, in 2009 new HIV infections were reduced by $17 \%$ over the previous 8 years. Since 2001, when the United Nations Declaration of Commitment on HIV/AIDS was signed, the number of new infections in sub-Saharan Africa is approximately $15 \%$ lower, which equated to about 400,000 fewer infections in 2008. In East Asia HIV incidence has declined by nearly $25 \%$ and in South and South East Asia by $10 \%$ in the same time period. In Eastern Europe, after a dramatic increase in new infections among injecting drug users, the epidemic has leveled off considerably. However, in some countries there are signs that HIV incidence is rising again [2].

Data from the WHO also show that there are more people living with HIV than ever before as, along with population growth, people are living longer due to the beneficial effects of antiretroviral therapy. The WHO estimates that since the availability of effective treatment in 1996, some 2.9 million lives have been saved [2]. Antiretroviral therapy has also made a significant impact on preventing new infections in children as more HIVpositive mothers gain access to treatment preventing 
mother-to-child transmission. Around 200,000 new infections among children have been prevented since 2001 [2].

Based on the deep knowledge gained about the HIV replication cycle, several drug targets have been identified over the years and effective treatment options are currently available. In accordance with Sharma and Garg [1], the current clinical therapeutic practice of using highly active antiretroviral treatment (HAART), is considered one of the most significant advances in the field of HIV therapy. Since the mid-1990s, HAART has made a remarkable contribution towards reducing mortality in patients [1].

Protease inhibitors (PIs) emerged in 1994 after the elucidation of the mechanism of replication of HIV. HIV requires active protease (PR) for processing Gag and Gag-Pol polyprotein precursors into mature structural proteins and replicative enzymes. HIV PR has therefore become one of the major targets for anti-HIV treatment, and PIs have proven to be highly effective antiretroviral drugs [3].

Darunavir, (3-[(4-amino-benzenesulfonyl)-isobutylamino]-1-benzyl-2-hydroxypropyl)-carbamic acid hexahydrofuro-[2,3-b]furan-3-yl ester, is a synthetic nonpeptidic PI developed in 1998 by the pharmaceutical company, Tibotec [4]. The compound was licensed in June 2006 in the United States and in February 2007 in the European Union [5].

Since its emergence many studies have demonstrated the efficacy of darunavir against HIV $[4,6]$, and this antiretroviral drug has become an important component of HAART.

In 2010 the Food and Drug Administration (FDA) approved new labeling for darunavir. The oral dose for treatment-experienced adult patients with no darunavir resistance-associated substitutions (V11I, V32I, L33F, $\mathrm{I} 47 \mathrm{~V}, \mathrm{I} 50 \mathrm{~V}, \mathrm{I} 54 \mathrm{~L}, \mathrm{I} 54 \mathrm{M}, \mathrm{T} 74 \mathrm{P}, \mathrm{L} 76 \mathrm{~V}, \mathrm{I} 84 \mathrm{~V}$ and $\mathrm{L} 89 \mathrm{~V}$ ) is $800 \mathrm{mg}$ darunavir once daily with ritonavir $100 \mathrm{mg}$ once daily and with food; for treatment-experienced adult patients with at least one darunavir resistance-associated substitution (V11I, V32I, L33F, I47V, I50V, I54L, I54M, T74P, L76V, I84V and L89V) the dose is $600 \mathrm{mg}$ darunavir twice daily taken with ritonavir $100 \mathrm{mg}$ twice daily and with food. For antiretroviral treatment-experienced patients genotypic testing is recommended. However, when genotypic testing is not feasible, a twice-daily dosing of darunavir/ritonavir 600/100 $\mathrm{mg}$ is recommended [7].

In this paper a review of the properties of darunavir is presented, along with its drug interactions and challenges that remain in the treatment of HIV/AIDS.

\section{Pediatric Treatment}

Since the introduction of antiviral treatment, mortality from HIV/AIDS has decreased and it has now become a chronic disease. This fact is of particular importance for the life expectancy of pediatric patients, as detailed by Nso-Roca et al. [8]. However, the treatment of HIVpositive children remains a challenge in HIV therapy, especially children younger than 1 year. Some research has shown that antiretroviral plasma concentrations are more frequently suboptimal in children younger than 1 year, which is related to greater antiretroviral treatment failure. This implies a considerable challenge in this population, which requires very long-term treatment [8]. Sosnik et al. [9] noted that pediatric HAART is especially difficult. Liquid formulations are essential for pediatric pharmacotherapy. Children under 7 are usually unable to swallow the solid medications and, to make adult medicines suitable for children, tablets or capsules are often processed to adjust dosages and facilitate swallowing. Significant safety, efficacy and quality concerns have arisen from such extemporaneous formulations [9].

Darunavir coadministered with ritonavir and with other antiretroviral agents was approved by the FDA for treating HIV infection in pediatric patients of 6 years of age and older. The dose should be based on body weight and should not exceed the dose for treatmentexperienced adults (600 $\mathrm{mg}$ darunavir/100 $\mathrm{mg}$ ritonavir). Darunavir should be taken with ritonavir twice daily and with food. A once-daily dosing should not be given to children. The safety and efficacy of darunavir/ritonavir for children from 3 to under 6 years of age has not been established. Darunavir is not recommended for children under 3 years of age [10].

There is a lower-dose $(75 \mathrm{mg})$ formulation of darunavir available for pediatric patients with HIV infection. These patients must range from 6 to 18 years of age and must weigh at least $44 \mathrm{lb}(20 \mathrm{~kg})$. For children weighing between 44 and $65 \mathrm{lb}, 375 \mathrm{mg}$ of darunavir and $50 \mathrm{mg}$ ritonavir twice daily is recommended. In the case of children weighing between 66 and $87 \mathrm{lb}, 450 \mathrm{mg}$ of darunavir and $60 \mathrm{mg}$ ritonavir twice daily is recommended and for children weighing $88 \mathrm{lb}$ or more the recommendation is $600 \mathrm{mg}$ of darunavir and $100 \mathrm{mg}$ ritonavir twice daily [11].

\section{Pharmacodynamic Properties}

\section{Efficacy and Therapeutic Safety}

The efficacy and safety of darunavir alone and administered with ritonavir have been demonstrated in 
many studies [12-15]. The results showed that darunavir significantly improved virological and immunological outcomes compared with others PIs and was generally well tolerated. In agreement with Back et al. [6], darunavir has been designed to have a high genetic barrier to the development of resistance and has activity against wild-type HIV-1 virus and a wide range of PI-resistant viruses.

As was explained by Back et al. [6], darunavir is structurally similar to amprenavir. However, darunavir has two tetrahydrofuran rings that are fused to each other. This difference is very important to the darunavir activity as the bis-tetrahydrofuran moiety reverses the stereochemistry at the bond that links it to the rest of the molecule and allows additional interactions of darunavir with ASP29, a key amino acid of the HIV PR [6].

\section{Adverse Effects}

Darunavir may cause adverse effects. The most common side effects are gastrointestinal disturbances (abdominal pain, diarrhea, nausea and vomiting), nasopharyngitis and hypertriglyceridemia. It should not be administered to patients with severe hepatic dysfunction and should be used with caution in cases of moderate hepatic dysfunction [16].

Hypertriglyceridemia

Combination antiretroviral therapy has been associated with metabolic abnormalities such as increased triglycerides, increased cholesterol, insulin resistance, increased blood sugar and hyperlactatemia [17]. After chronic treatment even moderate toxicity may lead to serious complications. In accordance with Sharma and Garg [1], the resulting treatment failure not only affects the quality of a patient's life but also significantly adds to the economic burden of the health care system $[1,18]$.

\section{Resistance}

The major complication of antiretroviral treatment, in accordance with Sasková et al. [3], is the evolution of drug-resistant PR variants. It occurs due to rapid viral replication. Most PIs select viral species with one or more specific mutations in the PR coding region that confer resistance. Sasková et al. [3] have emphasized that a detailed understanding of the mechanism of resistance development for individual clinically available PIs is essential for early detection of treatment failure. Moreover, it could lead to the design of a new generation of PIs ca- pable of inhibiting even the highly resistant PR species from AIDS patients [3].

Darunavir seems to be extremely potent against wildtype HIV as well as a large panel of PI-resistant clinical isolates and shows a high genetic barrier to the development of antiretroviral resistance. The results of different research studies suggest that darunavir is a potential drug for the treatment of both naïve and PI-experienced HIV patients $[3,14]$.

Sasková et al. [3] have sequenced more than 60,000 samples of HIV between 2006 and 2008 and have demonstrated that the prevalence of darunavir resistance remains low. Only $5.8 \%$ of samples with mutation that confer resistance to any retroviral drugs showed a darunavir mutation score of 3 or more, which is suggestive of darunavir resistance [3].

Fun et al. [19] have investigated whether the genetic diversity of HIV-1 subtypes affects the genetic barrier of darunavir. They have found that polymorphisms in Gag can lower the genetic barrier of darunavir and facilitate selection of resistance and Gag mutations can induce low-level darunavir resistance independent of mutations in the viral PR [19].

\section{Pharmacokinetic Properties}

The pharmacokinetics of darunavir have been studied extensively [20-28]. Pharmacokinetic studies in which darunavir was administered alone showed that it has a bioavailability of around of $37 \%$. When darunavir was administered in combination with ritonavir, a potent inhibitor of CYP3A, the plasma concentration of darunavir was increased. The bioavailability, calculated in comparison with IV administration of darunavir plus ritonavir, increased to $82 \%$ [21]. As there was an increase in the amount of darunavir absorbed, this suggests that darunavir is susceptible to presystemic metabolism or an efflux effect, or both, and ritonavir contributes to the diminution of these effects. Furthermore, the first order elimination of darunavir is inhibited by ritonavir $[6,21]$.

Sekar et al. [23] have evaluated the effect of food on darunavir pharmacokinetics. The administration of darunavir with a low dose of ritonavir in the fasting state resulted in a decrease in darunavir Cmax (maximum plasma concentration) and AUClast (area under the plasma concentration-time curve) of approximately $30 \%$ compared with administration after a standard meal. Therefore, darunavir should be administered with a low dose of ritonavir and food, regardless of the type of food, 
as exposure to darunavir was shown not to be affected by the type of meal $[6,23]$.

Studies have demonstrated that darunavir, similar to many other PIs, is highly protein bound to both acid glycoprotein and albumin [6, 22, 25]. Sekar et al. [22] have demonstrated that the mean plasma protein binding of darunavir was $95.3 \%$ at a concentration of $500 \mathrm{ng}$ base$\mathrm{eq} / \mathrm{ml}$ in plasma (clinically relevant concentrations) and that darunavir was mainly bound to $\alpha_{1}$-acid glycoprotein and to a lesser extent to albumin [22].

The most important route of metabolism of darunavir is oxidative metabolism. It is metabolized by cytochrome P450 (CYP450) enzymes, mainly CYP3A. Some metabolites of darunavir showed activity 10 -fold less than darunavir against the wild-type virus [6].

Vermeir et al. [29] have illustrated that ritonavir, as a boosting therapy, changes the darunavir metabolism. In their study, darunavir was extensively metabolized in unboosted subjects, mainly by carbamate hydrolysis, isobutyl aliphatic hydroxylation and aniline aromatic hydroxylation and to a lesser extent by benzylic aromatic hydroxylation and glucuronidation. However, boosting with ritonavir resulted in a significant inhibition of carbamate hydrolysis, isobutyl aliphatic hydroxylation and aniline aromatic hydroxylation. It had no effect on aromatic hydroxylation at the benzylic moiety, whereas the excretion of glucuronide metabolites was markedly increased but still represented a minor pathway. The difference in unchanged darunavir as a percentage of total excretion of the administered dose between boosted and unboosted subjects was huge, $48.8 \%$ compared to $8.0 \%$, which is a result of the inhibition of darunavir metabolism by ritonavir [29].

\section{Drug Interactions}

Drug interactions are a practical concern for physicians treating HIV-infected patients [20]. In addition to HAART, which requires combinations of multiple antiretroviral drugs, patients frequently need to coadminister other medications for reasons including the prevention or treatment of opportunistic infections, treatment of concomitant illnesses, and management of antiretroviral side effects [6].

As described by Back et al. [6], not all drug-drug interactions are undesirable, and the illustration of this is the well-established pharmacokinetic enhancement effect of PIs by ritonavir [6]. However, many drug-drug interactions may result in therapeutic problems that require dose adjustments or even result in contraindications to their use.

Darunavir: Review of Its Properties, Use and Drug Interactions
Many interactions between darunavir/low-dose ritonavir and other drugs frequently administered to HIVpositive patients have been studied. Compounds that alter CYP3A4 activity and expression might influence darunavir concentrations and the combination of darunavir and ritonavir may unpredictably influence the concentrations of other concomitant drugs that are metabolized mainly via the CYP3A4 isoenzyme. In most cases these drug interactions with darunavir can be managed and it is rare that the coadministration of other drugs is contraindicated $[6,20,30]$. Table 1 shows details of most of these studies.

Rittweger and Arastéh [30] have detailed that although these interactions were studied mainly in HIVnegative healthy volunteers, the results should also apply to the targeted population of HIV-infected patients [30]. Another important point in drug-drug interaction studies is that considering the beneficial results of treatment for HIV, which are reflected in the increased life expectancy of patients, further studies on drug interactions are necessary as ageing brings new comorbidities and often concomitant use of different drugs.

\section{Biopharmaceutical Classification}

The majority of antiretrovirals are administered orally. For absorption of these drugs from the gastrointestinal tract the drug should be present in the solution state in gastrointestinal fluid, which forms a critical requirement for the absorption of poorly water-soluble drugs $[1,31]$.

The system proposed by Amidon et al. [32], the Biopharmaceutical Classification System (BCS), defines that the aqueous solubility/dissolution of the drug dose in the gastrointestinal fluids and the intestinal permeability of drug substances are the fundamental events controlling oral drug absorption $[1,32,33]$.

Following BCS guidelines, a drug substance is considered highly soluble when its highest dose strength dissolves in $250 \mathrm{ml}$ or less of aqueous media over a $\mathrm{pH}$ range of $1.0-7.5$ at $37^{\circ} \mathrm{C}$. Likewise, the permeability of the drug substance is considered high when in humans it is determined to be $\geq 90 \%$ (FDA) or $\geq 85 \%$ (EMEA) of an administered dose based on a mass balance determination or in comparison to an intravenous reference dose $[1,34,35]$. However, as highlighted by Sharma and Garg [1], there are other factors that have to be taken into consideration for the appropriate estimation of the bioavailability such as the effect of efflux and absorptive transporters,

Pharmacology 2012;90:102-109 
Table 1. Interactions between darunavir/low dose ritonavir and other drugs

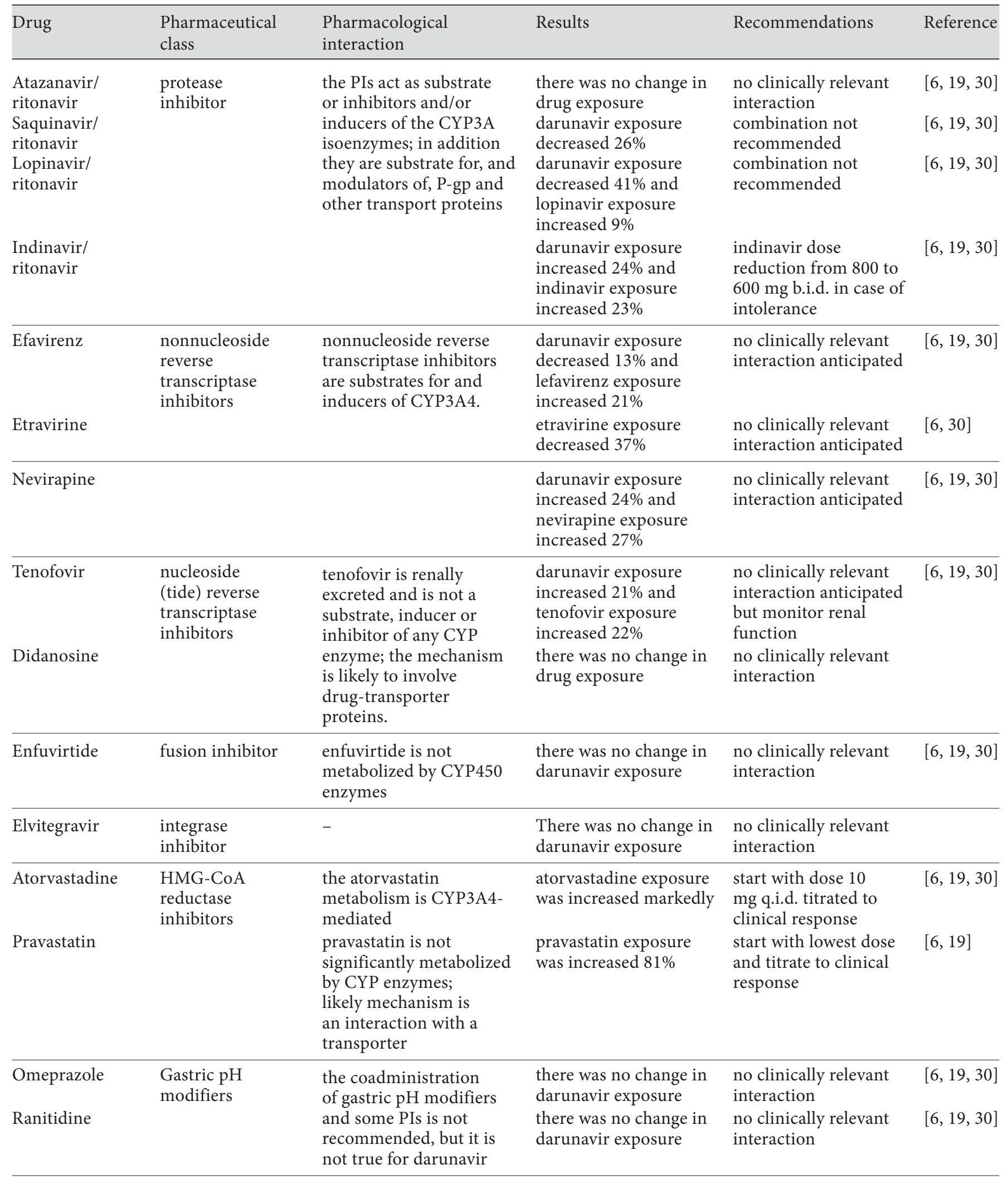


Table 1. (continued)

\begin{tabular}{|c|c|c|c|c|c|}
\hline Drug & $\begin{array}{l}\text { Pharmaceutical } \\
\text { class }\end{array}$ & $\begin{array}{l}\text { Pharmacological } \\
\text { interaction }\end{array}$ & Results & Recommendations & Reference \\
\hline Sildenafil & $\begin{array}{l}\text { phosphodiesterase } \\
\text { type-5 } \\
\text { inhibitor }\end{array}$ & $\begin{array}{l}\text { sildenafil is converted to } \\
\text { its primary metabolite by } \\
\text { the isoenzyme CYP3A4 }\end{array}$ & $\begin{array}{l}\text { sildenafil exposure was } \\
\text { increased markedly } \\
\text { (4-fold) }\end{array}$ & $\begin{array}{l}\text { maximum sildenafil } \\
\text { dose over a } 48 \text {-hour } \\
\text { period limited to } 25 \\
\text { mg }\end{array}$ & {$[6,19,30]$} \\
\hline $\begin{array}{l}\text { Oral } \\
\text { contraceptives } \\
\text { (ethinyl estradiol } \\
0.035 \mathrm{mg} \text { and } \\
\text { norethindrone } \\
1.0 \mathrm{mg} \text { ) }\end{array}$ & hormones & $\begin{array}{l}\text { ethinyl estradiol } \\
\text { is metabolized by } \\
\text { CYP3A and glucuronyl } \\
\text { transferase }\end{array}$ & $\begin{array}{l}\text { ethinyl estradiol ( } 44 \%) \\
\text { and norethindrone } \\
(24 \%) \text { exposure was } \\
\text { decreased markedly }\end{array}$ & $\begin{array}{l}\text { alternative/additional } \\
\text { contraceptives } \\
\text { recommended }\end{array}$ & {$[6,19,30]$} \\
\hline Clarythromycin & $\begin{array}{l}\text { anti-infective and } \\
\text { antifungal agents }\end{array}$ & $\begin{array}{l}\text { both drugs inhibit } \\
\text { CYP3A4 }\end{array}$ & $\begin{array}{l}\text { darunavir exposure } \\
\text { was decreased } 13 \% \\
\text { and clarythromycin } \\
\text { exposure was increased } \\
57 \%\end{array}$ & $\begin{array}{l}\text { no change in dosing, } \\
\text { except for renal } \\
\text { impairment }\end{array}$ & {$[6,30]$} \\
\hline Ketoconazole & & & $\begin{array}{l}\text { darunavir exposure } \\
\text { was increased } 42 \% \text { and } \\
\text { ketoconazole exposure } \\
\text { was increased } 212 \%\end{array}$ & $\begin{array}{l}\text { no change in dosing } \\
\text { (max. dose } 200 \mathrm{mg} \\
\text { q.i.d.) }\end{array}$ & {$[6,30]$} \\
\hline Sertraline & $\begin{array}{l}\text { selective serotonin } \\
\text { reuptake inhibitors }\end{array}$ & $\begin{array}{l}\text { they are both highly } \\
\text { protein bound and }\end{array}$ & $\begin{array}{l}\text { sertraline exposure was } \\
\text { decreased } 49 \%\end{array}$ & $\begin{array}{l}\text { monitor and titrate if } \\
\text { necessary }\end{array}$ & {$[6,19,30]$} \\
\hline Paroxetine & & $\begin{array}{l}\text { metabolized through } \\
\text { CYP3A4 (sertraline) or } \\
\text { CYP2D6 (paroxetine) }\end{array}$ & $\begin{array}{l}\text { paroxetine exposure } \\
\text { was decreased } 39 \%\end{array}$ & & {$[6,19,30]$} \\
\hline Methadone & narcotic analgesic & $\begin{array}{l}\text { ritonavir is an inducer } \\
\text { of the metabolism of } \\
\text { methadone }\end{array}$ & $\begin{array}{l}\text { methadone exposure } \\
\text { was decreased } 16 \%\end{array}$ & $\begin{array}{l}\text { no a priori methadone } \\
\text { dose adjustment } \\
\text { needed }\end{array}$ & {$[6,19,30]$} \\
\hline
\end{tabular}

intestinal metabolizing enzymes (CYP3A4 and UDPglucuronosyl transferases) and food [1].

It is known that darunavir is rapidly absorbed from the intestine after oral administration, reaching peak plasma concentrations after $2.5-4.0 \mathrm{~h}[6,20,21,36]$. It is also known that P-glycoprotein expressed in intestinal epithelial cells is able to decrease the absorption of orally administered PIs, and low levels of intestinal absorption together with CYP450 activity are major factors in the reduced bioavailability of these drugs $[1,36]$.

Fujimoto et al. [36] have demonstrated that P-glycoprotein mediates the efflux transport of darunavir in the apical membranes of Caco-2 cells. Darunavir was revealed to be a transport substrate of P-glycoprotein in Caco-2 cells and in MDR1 genetransfected renal LLC-PK1 cells. Furthermore, the mechanisms of action of ritonavir in terms of improving the bioavailability of darunavir were shown to involve the inhibition of the efflux transport systems of the intestinal lumen in addition to the intestinal/hepatic metabolism [36].

The relevance of the efflux transport phenomenon was illustrated by Sosnik et al. [9] using published studies on indinavir as examples. Indinavir was initially categorized as a class IV drug according to the BCS due to its apparently low permeability after oral intake. However, the drug was later reclassified as class II, indicating the ability of the molecule to intrinsically cross the intestinal barrier in the absence of active efflux mechanisms [9].

Although the intestinal absorption of darunavir has been considered to be intermediate-to-high when using Caco-2 monolayers [6], darunavir classification according to the BCS is not defined. Its permeability is not defined and there are no published studies on its solubility according to the BCS criteria. However, some inferences can be made about the biopharmaceutical classification of darunavir. As was detailed in Pharmacokinetic Properties, darunavir is always recommended to be co- 
administered with a low dose of ritonavir. Ritonavir, as a potent inhibitor of CYP3A and a possible substrate of P-glycoprotein, was shown to improve darunavir's bioavailability from 37 to $82 \%$ [21]. Moreover, these medicines have to be administered with food, which, as described by Sekar et al. [21], improves the bioavailability of darunavir by $30 \%$ [21]. Taking this data into account, it is possible to say that darunavir, when administered with ritonavir, can behave like a highly permeable drug substance and its biopharmaceutical classification may be in class I or II depending on its solubility. Darunavir is a drug of relatively low aqueous solubility [37] and, therefore, it is likely to be classified as class II. These inferences are critical because they illustrate that dissolution testing is a crucial test for a darunavir/ritonavir dosage form. Furthermore, dissolution testing could be useful for the development of an in vivo-in vitro correlation.

\section{Conclusion}

Darunavir, as a component of the group of a new generation of PIs, represents a great advantage in HIV/AIDS treatment since it has shown good efficacy against wildtype HIV-1 virus and a wide range of PI-resistant viruses. This PI, given in combination with ritonavir, might be classified as BCS class II due to the inhibition of metabolic pathways by ritonavir, resulting in darunavir having an effective high permeability value. While a cure for HIV/AIDS remains a long-term commitment there is still much to achieve and two of the biggest challenges are to develop a safe pediatric treatment and to improve the quality of life of the patient by developing a treatment with few or no side effects and with a low pill burden to reduce the frequency of administration by increasing bioavailability and overall exposure.

\section{Acknowledgements}

The authors thank Fapesp, CNPq, FUNDUNESP and PADC-UNESP for their financial support.

\section{References}

1 Sharma P, Garg S: Pure drug and polymer based nanotechnologies for the improved solubility, stability, bioavailability and targeting of anti-HIV drugs. Adv Drug Deliv Rev 2010;62:491-502.

2 World Health Organization: AIDS epidemic update. 2009. http://www.who.int/ mediacentre/news/releases/2009/hiv_ aids_20091124/en/index.html (accessed August 2011).

-3 Sasková KG, Kozísek M, Rezácová P, Brynda J, Yashina T, Kagan RM, Konvalinka J: Molecular characterization of clinical isolates of human immunodeficiency virus resistant to the protease inhibitor darunavir. J Virol 2009;83:8810-8818.

4 Ghosh AK, Kincaid JF, Cho W, Walters DE, Krishnan K, Hussain KA, Koo Y, Cho H, Rudall C, Holland L, Buthod J: Potent HIV protease inhibitors incorporating high-affinity p2-ligands and (r)-(hydroxyethylamino)sulfonamide isostere. Bioorg Med Chem Lett 1998;8:687-690.

5 Gyseghem E, Stokbroekx S, Armas HN, Dickens J, Vanstockem M, Baert L, Rosier J, Schueller L, Mooter G: Solid state characterization of the anti-HIV drug TMC114: interconversion of amorphous TMC114, TMC114 ethanolate and hydrate. Eur J Pharm Sci 2009;38:489-497.
6 Back D, Sekar VJ, Hoetelmans RM: Darunavir: pharmacokinetics and drug interactions. Antivir Ther 2008;13:1-13.

7 Food and Drug Administration: New labeling approved for Prezista (darunavir). 2010. http://www.fda.gov/ForConsumers/ ByAudience/ForPatientAdvocates/HIV andAIDSActivities/ucm236771.htm (accessed August 2011).

$\checkmark 8$ Nso-Roca AP, Larru B, Bellón JM, Mellado MJ, Ramos JT, González MI, Navarro ML, Muñoz-Fernández MA, José MI: Niveles plasmáticos de antirretrovirales en niños con infección por el virus de la inmunodeficiencia humana. Influencia del género y de la edad. Enferm Infecc Microbiol Clin 2010;28:278-283.

$\checkmark 9$ Sosnik A, Chiappetta DA, Carcaboso AM: Drug delivery systems in HIV pharmacotherapy: what has been done and the challenges standing ahead. J Control Release 2009;138:2-15.

10 Food and Drug Administration: Pediatric focused safety review: darunavir ethanolate (Prezista). 2010. http://www.fda.gov/ downloads/AdvisoryCommittees/CommitteesMeetingMaterials/PediatricAdvisoryCommittee/UCM235901.pdf (accessed August 2011).
11 New drugs. Drugs News 2009;34:125 (source: Medical News Today, February 12, 2009, www.prezista.com).

12 Curran A, Gutirerrez M, Deig E, Mateo G Lopez RM, Imaz A, Crespo M, Ocaña I, Domingo P, Ribera E: Efficacy, safety and pharmacokinetics of 900/100 mg of darunavir/ritonavir once daily in treatment-experienced patients. J Antimicrob Chemother 2010;65:2195-2203.

13 Haubrich R, Berger D, Chiliade P, Colson A, Conant M, Gallant J, Wilkin T, Nadler J, Pierone G, Saag M, Baelen B, Lefebvre E: Week 24 efficacy and safety of TMC114/ ritonavir in treatment-experienced HIV patients. Aids 2007;21:F11-F18.

$\checkmark 14$ Meyer S, Azijn H, Surleraux D, Jochmans D, Tahri A, Pauwels R, Wigerinck P, Béthune M-P: TMC114, a novel human immunodeficiency virus type 1 protease inhibitor active against protease inhibitorresistant viruses, including a broad range of clinical isolates. Antimicrob Agents Chemother 2005;49:2314-2321.

15 Ripamonti D, Arribas J, Hill A, Pulido F, Moecklinghoff C, Nelson M: Non-inferior efficacy shown across different efficacy endpoints in the MONET trial of darunavir/ ritonavir (DRV/r) monotherapy. 12th European Aids Conference/EACS, Cologne, 2009, poster PS4/1. 
16 Martindale: The Complete Drug Reference, ed 36. Philadelphia, Pharmaceutical Press, 2009.

17 Tibotec Inc: Prezista ${ }^{\mathrm{TM}}$, directions for use. 2008. www.accessdata.fda.gov/drugsatfda docs/label/2008/021976s003s004lbl.pdf.

18 Tomaka F, Lefebvre E, Sekar V, Baelen B, Vangeneugden T, Vandevoorde A, Duvauchelle T, Miralles D: Similar changes in metabolic parameters of darunavir and atazanavir each coadministered with low-dose ritonavir in healthy volunteers (TMC114-C159). American Conference for the Treatment of HIV (ACTHIV), Dallas, 2007. http:// www.ihlpress.com/pdf\%20files/hivdart06 presentations/Tomakapdf.pdf.

19 Fun A, Jong D, Nijhuis M: The genetic barrier of darunavir is decreased by Gag polymorphisms. 2011. 18th Conference on Retroviruses and Opportunistic Infections, Boston,2011.http://www.retroconference.org/ 2011/PDFs/603.pdf.

20 Back D, Sekar V, Lefebvre E, Pauw M, Paepe E, Vangeneugden T, Hoetelmans R: Use of darunavir (TMC114) in combination with other drugs: guidance from pharmacokinetic studies. 8th International Congress on Drug Therapy in HIV Infection, Glasgow, 2006, poster PL5.1.

21 Sekar VJ, Guzman S, Stevens T, DePaepe E, Lefebvre E, Hoetelmans R: Absolute bioavailability of TMC114, administered in the absence and presence of low dose ritonavir. 7th International Workshop on Clinical Pharmacology of HIV Therapy, London, 2006, abstract 86.

22 Sekar VJ, Spinosa-Guzman S, Lefebvre E, Hoetelmans R: Clinical pharmacology of TMC114-a new HIV protease inhibitor. 16th International AIDS Conference, Toronto, 2006, poster TUPE 0083.
23 Sekar VJ, Kestens D, Spinosa-Guzman S, Pauw M, Paepe E, Vangeneugden T, Lefebvre E, Hoetelmans RM: The effect of different meal types on the pharmacokinetics of darunavir (TMC114)/ritonavir in HIV-negative healthy volunteers. J Clin Pharmacol 2007;47:479-484.

24 Sekar VJ, Lefebvre E, Paepe E, Marez T, Pauw M, Parys W, Hoetelmans RM: Pharmacokinetic interaction between darunavir boosted with ritonavir and omeprazole or ranitidine in human immunodeficiency virus-negative healthy volunteers. Antimicrob Agents Chemother 2007;51:958-961.

25 Sekar VJ, Abeele CV, Baelen B, Vis P Lavreys L, Pauw M, Dincq S, Vangeneugden T, Spinosa-Guzman S, Hoetelmans R: Pharmacokinetic-pharmacodynamic analyses of once-daily darunavir in the ARTEMIS study. 9th International Workshop on Clinical Pharmacology of HIV Therapy, New Orleans, 2008, poster $\mathrm{P} 42$.

-26 Sekar VJ, Lefebvre E, Pauw M, Vangeneugden T, Hoetelmans RM: Pharmacokinetics of darunavir/ritonavir and ketoconazole following co-administration in HIVhealthy volunteers. Br J Pharmacol 2008;66: 215-221.

-27 Sekar VJ, Spinosa-Guzman S, Paepe E, Pauw $M$, Vangeneugden T, Lefebvre E, Hoetelmans RM: Darunavir/ritonavir pharmacokinetics following coadministration with clarithromycin in healthy volunteers. J Clin Pharmacol 2008;48:60-65.

28 Tomi M, Nishimura T, Nakashima E: Mother-to-fetus transfer of antiviral drugs and the involvement of transporters at the placental barrier. J Pharm Sci 2011;100:3708-3718.

29 Vermeir M, Lachau-Durand S, Mannens G, Cuyckens F, Hoof B, Raoof A: Absorption, metabolism, and excretion of darunavir, a new protease inhibitor, administered alone and with low-dose ritonavir in healthy subjects. Drug Metab Dispos 2009;37:809-820.
30 Rittweger M, Arastéh K: Clinical pharmacokinetics of darunavir. Clin Pharmacokinet 2007;46:739-756.

31 Sinha S, Ali M, Baboota S, Ahuja A, Kumar A, Ali J: Solid dispersion as an approach for bioavailability enhancement of poorly water-soluble drug ritonavir. AAPS J 2010;11: 518-527.

32 Amidon GL, Lennernas H, Shah VP, Crison JR: A theoretical basis for a biopharmaceutic drug classification: the correlation of in vitro drug product dissolution and in vivo bioavailability. Pharm Res 1995;12:413-420.

-33 Dahan A, Miller JM, Amidon GL: Prediction of solubility and permeability class membership: provisional BCS classification of the world's top oral drugs. AAPS J 2009;11: 740-746.

34 European Medicines Agency: Pre-authorization evaluation of medicines for human use. Committee for Medicinal Products for Human Use. Guideline on the investigations of bioequivalence. 2008. http://www.ema. europa.eu/pdfs/human/qwp/140198enrev1. pdf.

35 Food and Drug Administration: Guidance for industry: waiver of in vivo bioavailability and bioequivalence studies for immediate-release solid oral dosage forms based on a biopharmaceutics classification system. 2000. http://www.fda.gov/downloads/ Drugs/GuidanceComplianceRegulatoryInformation/Guidances/ucm070246.pdf.

-36 Fujimoto H, Higuchi M, Watanabe H, Koh Y, Ghosh AK, Mitsuya H, Tanoue N, Hamada A, Saito H: P-glycoprotein mediates efflux transport of darunavir in human intestinal Caco-2 and ABCB1 gene-transfected renal LLC-PK1 cell lines. Biol Pharm Bull 2009; 32:1588-1593.

37 Predicting ACD/pKa DB. Advanced Chemistry Development Inc. Copyright 1994-2002. 